\title{
FOREIGN OWNERSHIP, FINANCIAL LEVERAGE DAN PRICE TO EARNING RATIO (P/E)
}

\author{
Pristin Prima Sari ${ }^{1}$, Sri Hermuningsih ${ }^{2}$ \\ ${ }^{1,2}$ Universitas Sarjanawiyata Tamansiswa Yogyakarta \\ Pristin.primas@gmail.com,Hermun_feust@yahoo.co.id
}

Diterima: Februari 2018; Disetujui: Maret 2018; dipublikasikan: April 2018

\begin{abstract}
ABSTRAK
Penelitian ini bertujuan untuk menemukan bukti empiris pengaruh Financial Leverage, Foreign Ownership terhadapPrice To Earning Ratio (P/E) pada perusahaan-perusahaan non keuangan di Bursa Efek Indonesia (BEI) tahun 2012-2016. Sampel dalam penelitian ini adalah 46 perusahaan non keuangan di Bursa Efek Indonesia tahun 2012-2016. Data berupa panel dengan metode fixed effect dengan variabel kontrol inflasi dan firm size. Alat analisis menggunakan EViews 9th Edition. Hasil dari penelitian ini adalah secara simultan menunjukkan bahwa financial leverage dengan proksi Debt to Equity (DER), foreign ownership, Inflasi dan firm sizeberpengaruh positifsignifikan (signifikansi 0,000$)$ terhadap price to earning ratio $(\mathrm{P} / \mathrm{E})$. Secara parsial menunjukkan bahwa Financial leverage berpengaruh negatif signifikan (signifikansi 0,000) terhadap P/E. Foreign ownership berpengaruh negatif signifikan (signifikansi 0,000) terhadap P/E. Inflasi tidak berpengaruh (signifikansi 0,000) terhadap P/E. Firm Size berpengaruh negatif signifikan (signifikansi 0,000) terhadap P/E. Penelitian ini bermanfaat bagi pemegang saham, manajemen perusahaan dan pemerintah dalam mengambil kebijakan yang berkaitan dengan foreign ownership, financial leverage dan price to earning ratio $(\mathrm{P} / \mathrm{E})$.
\end{abstract}

Kata kunci: Financial Leverage, Foreign Ownership, Price to Earning Ratio, BEI

\begin{abstract}
This study aims to find empirical evidence of the influence of Financial Leverage, Foreign Ownership to Price To Earning Ratio $(P / E)$ on non-financial companies in Indonesia Stock Exchange (IDX) in 2012-2016. The samples in this research are 46 non-financial companies in Indonesia Stock Exchange in 2012-2016. Data in the form of panel with fixed effect method with inflation control variable and firm size. We use E-Views 9th Edition for analysis data. The results of this study simultaneously show that financial leverage with Debt to Equity (DER) as a proxy, foreign ownership, Inflation and firm size proportion have significant positive effect $(0,000$ significance) on price to earning ratio $(P / E)$. Partially shows that Financial leverage has negative significant effect (significance 0.000) to $P / E$. Foreign ownership has negative significant effect (significance 0,000) to P / E. Inflation has no effect (significance 0.000) to P / E. Firm Size has negative significant effect (significance 0.000) to $P$ / E. This research is useful for shareholders, corporate and government management in taking policies related to foreign ownership, financial leverage and price to earnings ratio $(P / E)$.
\end{abstract}

Keywords : Financial Leverage, Foreign Ownership, Price to Earning Ratio, IDX 


\section{PENDAHULUAN}

Keberadaan pasar modal sangat di butuhkan oleh masyarakat, khususnya investor yang ingin melakukan investasi saham di pasar modal. Investor membutuhkan beberapa informasi untuk mengambil kebijakan berinvestasi di pasar modal. Beberapa informasi yang dibutuhkan investor adalah faktor fundamental perusahaan misalnya laba yang dihasilkan perusahaan dan faktor ekonomi makro suatu negara. Selain itu, informasi tentang harga saham sangat dibutuhkan oleh investor. Dengan demikian para investor bisa menginvestasikan dananya berdasarkan return yang akan di peroleh.) Bagi emiten mencari dana melalui pasar modal merupakan pilihan pembiayaan (Hermuningsih 2012)

Price to earning ratio (P/E) mencerminkan harga saham berdasarkan laba setiap lembar saham perusahaan. Pasar saham akan merespon kinerja perusahaan dalam perolehan laba. Pasar saham akan merespon dalam bentuk kenaikan harga saham. Price to earning ratio (P/E) juga mencerminkan sensitivitas investor terhadap laba perusahaan. Investor cenderung lebih memperhatikan laba yang diperoleh perusahaan saat membeli dan menjual saham perusahaan. Dengan demikian price to earning ratio $(\mathrm{P} / \mathrm{E})$ merupakan faktor penilaian perusahaan.

Basu (1977) menemukan bahwa price earning ratio (P/E) merupakan indikator kinerja investasi perusahaan kedepan. $\mathrm{P} / \mathrm{E}$ menunjukkan kualitas investasi. $\mathrm{P} / \mathrm{E}$ yang rendah secara tidak eksplisit menunjukkan investasi yang baik sementara $\mathrm{P} / \mathrm{E}$ yang tinggi mengindikasikan perspektif yang lemah untuk investasi. Jika rasio $\mathrm{P} / \mathrm{E}$ perusahaan lebih tinggi dari pada perusahaan lain maka itu berarti perusahaan dengan $\mathrm{P} / \mathrm{E}$ yang lebih tinggi memiliki kemungkinan lebih besar untuk pertumbuhan pendapatan yang lebih tinggi di masa depan dibandingkan dengan yang lain. Hal ini juga membantu untuk membandingkan nilai saham dan mengambil keputusan investasi yang tepat.

Penelitian terdahulu menghasilkan temuan yang berbeda berkaitan dengan intepretasi tinggi rendahnya price earning ratio (P/E). McWilliams (1966) menemukan bahwa P/E yang rendah menawarkan kinerja investasi yang lebih baik daripada saham dengan $\mathrm{P} / \mathrm{E}$ yang tinggi. Namun, Dave dkk (1998) menemukan bahwa P/E yang rendah memberikan return yang rendah dan begitu pula sebaliknya.

Para investor tertarik untuk berinvestasi pada saham-saham yang memiliki rasio P/E rendah karena rasio P/E rendah menunjukkan bahwa harga saham tersedia dengan biaya murah yaitu return investasi yang lebih tinggi. Saham dengan P/E yang lebih tinggi dianggap sebagai investasi yang kurang menarik. Di sisi lain, Price earning ratio merupakan indikator perubahan harga saham atas laba yang diperoleh perusahaan. Investor sangat memperhatikan pertumbuhan laba yang dihasilkan perusahaan. Laba perusahaan yang tinggi maka akan meningkatkan penilaian pasar. Selanjutnya, Rasio P/E pada umumnya berguna untuk membandingkan valuasi perusahaan sejenis di sektor atau kelompok sejenis.

Goyal et al (2003) menemukan bahwa portofolio saham perusahaan secara relatif memiliki P/E yang rendah biasanya menunjukkan rata-rata perputaran yang tinggi. Tetapi masalah meningkat ketika portofolio saham dengan $\mathrm{P} / \mathrm{E}$ yang rendah maka secara umum investor kehilangan banyak kesempatan investasi dalam kondisi ini. Karena perusahaan memiliki P/E yang rendah tidak menawarkan kelebihan return daripada perusahaan yang memiliki pertumbuhan cepat dan menawarkan kelebihan P/E yang tinggi. Azizi (1999) menemukan bahwa P/E merupakan faktor penentu harga dan merupakan indeks yang berkaitan dengan perhatian investor aktif terhadap perusahaan.

Price to Earning Ratio $(P / E)$ merupakan rasio untuk menghitung nilai perusahaan. Tandelilin (2008) menemukan bahwa price to earning ratio $(\mathrm{P} / \mathrm{E})$ dapat digunakan untuk mengukur nilai perusahaan. Abbazi dan paghe (2013) menemukan bahwa price earning ratio $(\mathrm{P} / \mathrm{E})$ berpengaruh signifikan terhadap return saham pada Tehran Stock Exchange.

Terdapat dua jenis investor saham yaitu investor domestik (domestic investor) dan investor asing (foreign Investor). Investor yang membeli saham perusahaan di Bursa Efek 
Indonesia (BEI) disebut foreign ownership. Foreign ownership merupakan prosentase kepemilikan asing didalam perusahaan yang terdaftar di BEI. Foreign investor akan mengapresiasi positif laba yang diperoleh perusahaan.

Penelitian terdahulu telah menemukan bukti empiris hubungan foreign ownership dan price to earning ratio. Chira dan Houmes (2015) menemukan bahwa insider ownership akan menghasilkan PER yang lebih tinggi.Foreign ownership membuat pengawasan perusahaan menjadi lemah sehingga perusahaan berkinerja kurang baik. Kinerja yang turun dapat menurunkan nilai perusahaan. Laba menurun maka harga perusahaan juga menurun. Disamping itu, Myers and majluf (1977) juga menemukan bahwa harga saham cenderung menurun ketika perusahaan mengumumkan penerbitan saham baru. Namun, Bai dkk (2004) menemukan bahwa foreign ownership meningkatkan penilaian pasar. Sehingga foreign ownership dapat meningkatkan price to earning ratio.

Penelitian terdahulu juga telah menemukan bukti empiris pengaruh financial leverage, foreign ownership dan nilai perusahaan. Agustina (2006) menemukan bahwa leverage menurunkan kepemilikan asing. Li dkk (2009) menemukan bahwa chinese firms yang memiliki foreign ownership yang tinggi maka tidak memiliki hutang yang tinggi sehingga sesuai dengan trade off theory. Agency Theory (Jensen Dan Meckling, 1976) menemukan bahwa terdapat agency conflict antara manager dan pemegang saham. Terdapat agency cost untuk mengawasi tindakan manager. Jensen (1986) menemukan bahwa struktur modal dapat meningkatkan nilai perusahaan. Dengan hutang perusahaan akan diawasi secara ketat oleh kreditor sehingga kinerja dan nilai perusahaan meningkat.

Disamping itu, investor juga merespon positif dari tindakan hutang perusahaan. Hutang mencerminkan kemampuan kondisi perusahaan dimasa mendatang tetap positif. Selain itu, hutang dapat menurunkan pajak sehingga laba perusahaan dapat meningkat. Hutang dapat meningkatkan penilaian pasar. Hutang memberikan sinyal positif bahwa perusahaan akan ekspansi pasar. Sehingga, hutang merupakan sinyal positif bagi pasar saham (Ross, 1977). Dengan demikian, Hutang dapat meningkatkan nilai price to earning ratio $(\mathrm{P} / \mathrm{E})$. Modigliani and Miller (1963) menemukan bahwa dengan hutang maka pajak akan menurun sehinggadapat meningkatkan nilai perusahaan. Peningkatan hutang dapat meningkatkan laba dari pengurangan pajak perusahaan.

Penelitian terdahulu menunjukkan hasil yang berbeda tentang financial leverage dan price to earning ratio (P/E). Mulyani dan Pitaloka (2017) menemukan bahwa debt to equity ratio $(\mathrm{D} / \mathrm{E})$ berpengaruh signifikan terhadap price to earning ratio $(\mathrm{P} / \mathrm{E})$. Sartono dan munir (1999) menemukan bahwa debt to equity ratio memiliki pengaruh yang signifikan terhadap price to earning ratio (P/E). Namun, Malkiel Dan Cragg (1970) dan Mahmood dan Zakaria (2007) bahwa Struktur modal dapat menurunkan price to earning ratio (P/E). Moeliadji (2010) menemukan bahwa debt to equity ratio $(\mathrm{D} / \mathrm{E})$ tidak berpengaruh signifikan terhadap price earning ratio (P/E). Marli dkk (2010) menemukan bahwa debt to equity ratio (D/E) menurunkan price to earning ratio $(\mathrm{P} / \mathrm{E})$.

Kondisi makro ekonomi perusahaan juga mempengaruhi besarnya price to earning ratio $(\mathrm{P} / \mathrm{E})$. Inflasi merupakan faktor makro ekonomi perusahaan. Pada saat inflasi harga barang secara umum meningkat sehingga hal ini dapat mempenagruhi pendapatan laba perusahaan. Penelitian terdahulu menemukan perbedaan hasil berkaitan dengan inflasi dan return saham. Abbazi dan Paghe (2013) menemukan bahwa Consumer Price Index (CPI) dan Industry Price Index (IPI) tidak berpengaruh signifikan negatif terhadap return saham perusahaan di Tehran Stock Exchange. Bayati (2005) menemukan bahwa inflasi tidak berpengaruh signifikan terhadap investasi di Bursa Saham Tehran.

Penelitian ini menguji studi empiris sensitivitas investor asing dalam merespon laba perusahaan. Hal itu dapat dilihat pada besarnya harga saham perusahaan dibandingkan laba per lembar saham. Fokus penelitian ini untuk menemukan bukti empiris pengaruh Financial Leverage, Foreign Ownership terhadap price to earning ratio $(\mathrm{P} / \mathrm{E})$ pada perusahaanperusahaan non keuangan di Bursa Efek Indonesia (BEI). 


\section{Foreign Ownership Dan Price Earning Ratio (P/E)}

Foreign Ownershipadalah proporsi jumlah saham yang dimiliki oleh investor asing baik institusi maupun personal (Wiwattanakantang, 1999).Teori Pecking Order (Myers and Majluf, 1984) menjelaskan bahwa terdapat asimetri informasi di dalam perusahaan. Asimetri informasi adalah kesenjangan perolehan informasi tentang perusahaan antara pemegang saham dengan manajemen perusahaan. Manajemen perusahaan lebih mengetahui kondisi perusahaan daripada pemegang saham. Apabila manajemen perusahaan melakukan tindakan yang sama dengan tujuan pemegang saham maka nilai perusahaan dapat meningkat. Foreign ownership dapat mengawasi kinerja perusahaan secara ketat. Sehingga Foreign Ownershipdapat meningkatkan nilai perusahaan (Bai dkk, 2004).

Price earning ratio $(\mathrm{P} / \mathrm{E})$ merupakan indikator penilaian perusahaan. Apabila laba perusahaan meningkat maka harga saham perusahaan juga meningkat. Jadi, Foreign ownership dapat meningkatkan kinerja dan penilaian perusahaan. Salvatore (2005) menemukan bahwa saham-saham dari mayoritas kepemilikan asing memiliki return yang lebih tinggi daripada saham-saham perusahaan kepemilikan domestik.Foreign Ownership memiliki pengaruh positif pada penilaian perusahaan (Farooque dkk, 2007). Berdasarkan teori dan penelitian terdahulu maka perumusan hipotesis adalah sebagai berikut:

\section{Financial Leverage Dan Price to Earning Ratio (P/E)}

Financial leverage adalah penggunaan dana dengan beban tetap dengan harapan atas penggunaan dana tersebut akan memperbesar pendapatan per lembar saham (earning per shareEPS). Pendanaan bernilai positif apabila pendanaan tersebut meningkatkan pendapatan per lembar saham (earning per share-EPS). Financial leverage merupakan komponen dari hutang, common equity, preferred equity yang digunakan untuk pendanaan total aset perusahaan, operasional, dan pertumbuhan keuangan (Goel dkk, 2015).

Hutang dapat menurunkan pajak sehingga laba perusahaan dapat meningkat. Hutang dapat meningkatkan penilaian pasar. Hutang merupakan sinyal positif kepada pasar (Ross, 1977).Perusahaan memiliki prospek positif dan perusahaan melakukan ekspansi pasar. Perusahaan yang memiliki hutang akan diawasi secara ketat oleh kreditur sehingga perusahaan berkinerja dengan baik. Perusahaan yang berkinerja dengan baik dapat menghasilkan laba yang tinggi. Dengan demikian, Hutang dapat meningkatkan nilai price to earning ratio (P/E). Modigliani dan Miller (1963) menemukan bahwa pajak berdampak pada nilai perusahaan. Peningkatan hutang dapat meningkatkan laba dari pengurangan pajak perusahaan.Perusahaan yang menggunakan hutang memiliki nilai perusahaan yang lebih tinggi daripada perusahaan tanpa hutang. Fairfield (1994) menemukan bahwa price earning ratio dan pertumbuhan laba memiliki hubungan yang positif. Apabila pertumbuhan laba meningkat maka akan meningkatkan price earning ratio. Modigliani dan Miller (1958) menemukan bahwa struktur modal perusahaan dapat meningkatkan nilai perusahaan.

Beberapa penelitian terdahulu telah menemukan bukti empiris pengaruh financial leverage meningkatkan price to earning ratio (P/E). Mulyani dan Pitaloka (2017) dan Sartono dan Munir (1999) menemukan bahwa debt to equity ratio (DER) berpengaruh signifikan terhadap price to earning ratio (P/E).Pietrovit (2016) menemukan bahwa price earning ratio( $(\mathrm{P} / \mathrm{E})$ yang tinggi mengindikasikan bahwa investor mempercayakan pertumbuhan laba meskipun laba saat ini rendah.

\section{METODE}

Penelitian ini menggunakan data tahunan dari laporan keuangan perusahaan sektor aneka industri, barang konsumsi dan sektor perdagangan, jasa dan investasi di Bursa Efek Indonesia (BEI) tahun 2012-2016. Pemilihan sampel menggunakan metode purposif sampling. Penelitian 
ini menggunakan metode Panel Lease Square dengan E-Views edisi 9 sebagai alat analisis data. Penelitian ini menggunakan uji asumsi klasik adalah heteroskedastisitas, multikolonieritas, normalitas, dan autokorelasi. Penelitian ini menggunakan Fixed Effect Method pada analisis multiple regression.Penelitian ini juga menggunakan uji $\mathrm{F}$ (uji simultan) untuk menguji model secara keseluruhan. Disamping itu, juga menggunakan uji T(uji parsial) pada masing-masing pengaruh variabel independen terhadap variabel dependen.

Persamaan Regresi dalam penelitian ini adalah sebagai berikut:

$\mathrm{Y}_{\mathrm{P} / \mathrm{E}}=\alpha+\beta_{1}$ Foreign $+\beta_{2}$ DER $+\beta_{3}$ inflasi $+\beta_{4}$ Size $+\mathrm{e}$

Keterangan:

$$
\begin{array}{ll}
\mathrm{Y}_{\mathrm{P} / \mathrm{E}} & =\text { Variabel Dependen price earning ratio } \\
\alpha & =\text { Konstanta } \\
\text { Foreign } & =\text { Kepemilikan asing } \\
\mathrm{DER} & =\text { debt to equity ratio } \\
\mathrm{Size} & =\text { ukuran perusahaan } \\
\mathrm{e}=\text { error } &
\end{array}
$$

\section{Variabel Dependen}

\section{Price To Earning ratio (P/E)}

Price Earning Ratio (P/E) (Tandelilin, 2008) adalah rasio yang membandingkan harga saham dengan laba setiap lembar saham.

\section{Rumus Price to Earning Ratio :}

\section{$\mathbf{P} / \mathbf{E}=$ Price per share}

\section{Earning per share}

\section{Variabel Independen}

\section{Financial Leverage}

Financial Leverage adalah suatu rasio yang menghitung besarnya hutang perusahaan. Penelitian ini menggunakan debt to equity ratio (DER) sebagai proksi dari financial leverage (Shyu, 2011). Debt to equity ratio (DER) adalah analisis rasio yang menghitung perbandingan jumlah hutang perusahaan dengan jumlah ekuitas perusahaan.

\section{Rumus Financial Leverage : \\ DER $=\underline{\text { Total Debt }}$}

Total Equity

\section{Foreign Ownership}

Foreign Ownerhip adalah prosentase kepemilikan saham investor asing pada perusahaan yang terdaftar di Bursa Efek Indonesia. Foreign ownership dihitung dengan rasio prosentase. Penggunaan variabel Foreign ownership berdasarkan penelitian Bai dkk (2004) adalah dengan prosentase kepemilikan saham asing didalam perusahaan.

\section{Variabel Kontrol \\ Inflasi}

Inflasi adalah kenaikan harga barang dan jasa secara umum. Inflasi merupakan asah satu faktor ekonomi makro di suatu negara. Inflasi dihitung dengan indeks harga konsumen. Inflasi dapat mempengaruhi laba dan harga saham perusahaan. Yahya dkk (2001) menemukan bahwa terdapat pengaruh positif antara inflasi dan indeks harga saham.

\section{Firm Size}

Firm Size adalah ukuran besarnya perusahaan berdasarkan jumlah total aset perusahaan. Rumus firm size(Li et al, 2009)adalah Log natural (total aset).

\section{Rumus Firm Size:}

Firm Size = Ln(Total Aset $)$ 


\section{HASIL DAN PEMBAHASAN}

Tabel 4.1

Statistik Deskriptif

\begin{tabular}{|c|c|c|c|c|c|}
\hline & PER & DER & FO & INFLASI & Size \\
\hline Mean & 36.14406 & 1.110903 & 0.367195 & 5.482000 & 14.85503 \\
\hline Median & 19.59000 & 0.746050 & 0.307550 & 4.300000 & 14.61550 \\
\hline Maximum & 877.5400 & 7.390000 & 0.981800 & 8.380000 & 26.66318 \\
\hline Minimum & -554.0500 & 0.020000 & 0.000000 & 3.020000 & 6.651136 \\
\hline Std. Dev. & 131.2644 & 1.071548 & 0.333333 & 2.400439 & 1.942928 \\
\hline Skewness & 3.550224 & 2.444790 & 0.361933 & 0.318906 & 0.814472 \\
\hline Kurtosis & 27.49141 & 11.73628 & 1.680216 & 1.206140 & 9.514705 \\
\hline Jarque-Bera & 6231.522 & 960.5432 & 21.71404 & 34.73707 & 432.1589 \\
\hline Probability & 0.000000 & 0.000000 & 0.000019 & 0.000000 & 0.000000 \\
\hline Sum & 8313.133 & 255.5077 & 84.45482 & 1260.860 & 3416.657 \\
\hline Sum Sq. Dev. & 3945750. & 262.9410 & 25.44433 & 1319.523 & 864.4677 \\
\hline Observations & 230 & 230 & 230 & 230 & 230 \\
\hline
\end{tabular}

Sumber : Olah Data E-Views

Penelitian ini menggunakan sampel 46 perusahaan non keuangan di Bursa Efek Indonesia tahun 2012-2016. Berdasarkan tabel 4.1 Nilai probabilitas Jarque Bera sebesar 0,000. Nilai 0,000 menunjukkan nilai yang signifikan pada level 5\%. Variabel PER memiliki nilai rata-rata sebesar 36,14 kali, nilai maksimum sebesar 877 kali, dan nilai minimum sebesar -554,05. Variabel DER memiliki rata-rata sebesar $1,11 \%$, nilai maksimum sebesar $7,39 \%$ dan nilai minimum sebesar $2 \%$. Variabel Foreign Ownership memiliki nilai rata-rata sebesar $36,71 \%$, nilai maksimum sebesar 98,18\% dan nilai minimum sebesar 0. Variabel Inflasi memiliki nilai rata-rata sebesar 5,48\%, nilai maksimum sebesar $8,38 \%$ dan nilai minimum sebesar 3,02\%. Variabel Firm Size memiliki nilai rata-rata sebesar 14,85, nilai maksimum sebesar 26,66 dan nilai minimum sebesar 6,65 .

Tabel 4.2

Hasil Uji F Dan Uji T

\begin{tabular}{crrrr}
\hline \hline Variable & Coefficient & Std. Error & t-Statistic & Prob. \\
\hline \hline C & 51.43660 & 1.529454 & 33.63069 & 0.0000 \\
DER & -3.434558 & 0.097520 & -35.21887 & $0.0000^{*}$ \\
FO & -20.14180 & 0.385841 & -52.20235 & $0.0000^{*}$ \\
INFLASI & -0.090395 & 0.100630 & -0.898287 & 0.3702 \\
LNTA & -1.304285 & 0.080676 & -16.16702 & $0.0000^{*}$ \\
\hline \hline
\end{tabular}

Effects Specification

Cross-section fixed (dummy variables)

\begin{tabular}{llll}
\hline \hline R-squared & 0.986725 & Mean dependent var & 18.53600 \\
Adjusted R-squared & 0.983112 & S.D. dependent var & 5.083240 \\
S.E. of regression & 0.660594 & Akaike info criterion & 2.198306
\end{tabular}




\begin{tabular}{lrll} 
Sum squared resid & 78.54922 & Schwarz criterion & 2.945714 \\
Log likelihood & -202.8052 & Hannan-Quinn criter. & 2.499795 \\
F-statistic & 273.0534 & Durbin-Watson stat & 2.339357 \\
Prob(F-statistic) & $0.000000^{*}$ & & \\
\hline
\end{tabular}

Ket:

* Signifikan $1 \%$

** Signifikan 5\%

*** Signifikan $10 \%$

$Y_{\text {per }}=51,43-3,43 D E R-20,14 F O-1,3$ Size $+e$

Berdasarkan tabel 4.2 nilai F sebesar 273,05 dengan signifikansi sebesar 0,000. Sehingga dapat diketahui bahwa secara simultan financial leverage, foreign ownership, inflasi dan firm size berpengaruh signifikan positif terhadap price to earning ratio $(\mathrm{P} / \mathrm{E})$. Secara simultan pengaruh variabel financial leverage, foreign ownership, inflasi dan firm size dapat meningkatkan price to earning ratio (P/E) sebesar 273,05 dengan tingkat signifikansi sebesar $1 \%$. Selanjutnya, nilai adjusted R-Square sebesar 0,9831. Hal itu bearti bahwa variabel financial leverage, foreign ownership, inflasi dan firm size dapat mempengaruhi variabel price to earning ratio (P/E) sebesar 98,31\% dan 1,69\% dipengaruhi oleh variabel lain di luar model ini.

Tabel 4.2 menunjukkan bahwa nilai koefisien DER sebesar -3,43 dengan signifikansi sebesar 0,000. Secara parsial variabel DER berpengaruh signifikan negatif terhadap price to earning ratio $(\mathrm{P} / \mathrm{E})$ pada tingkat signifikansi $1 \%$. Financial leverage (DER) dapat menurunkan sebesar 3,43 harga saham dibandingkan laba setiap lembar saham. Hasil penelitian ini berbeda dengan penelitian oleh Mulyani dan Pitaloka (2017) dan Sartono dan Munir (1999) namun konsisten dengan hasil penelitian Malkiel Dan Cragg (1970), Marli dkk (2010) dan Mahmood dan Zakaria (2007). Malkiel Dan Cragg (1970), Marli dkk (2010) dan Mahmood dan Zakaria (2007) menemukan bahwa Struktur modal (DER) dapat menurunkan price to earning ratio $(\mathrm{P} / \mathrm{E})$.

Foreign Ownership memiliki nilai koefisien sebesar -20,14 dengan signifikansi besar 0,000. Secara parsial Foreign ownership berpengaruh signifikan negatif terhadap price to earning ratio $(\mathrm{P} / \mathrm{E})$. Foreign ownership dapat menurunkan harga saham perusahaan terhadap laba per lembar saham sebesar 20,14 pada tingkat signifikansi $1 \%$. Foreign ownership memberikan harga yang lebih rendah berdasarkan perolehan laba per lembar saham yang dihasilkan perusahaan. Hasil ini berbeda dengan Salvatore (2005) namun sama dengan penelitian yang dilakukan oleh Chira dan Houmes (2015). Chira dan Houmes (2015) menemukan bahwa insider ownership akan menghasilkan P/E yang lebih tinggi. Dengan demikian, outsider ownership dapat menurunkan nilai price to earning ratio $(\mathrm{P} / \mathrm{E})$.

Inflasi memiliki nilai koefisien -0,09 dengan signifikansi sebesar 0,37. Inflasi berpengaruh negatif tidak signifikan terhadap price to earning ratio $(\mathrm{P} / \mathrm{E})$. Inflasi tidak berpengaruh signifikan terhadap P/E. Inflasi di indonesia selama periode 2012-2016 tidak menurunkan price to earning ratio (P/E). Hasil penelitian ini berbeda dengan Yahya dkk (2001) namun sama dengan hasil penelitian Abbazi dan Paghe (2013). Yahya dkk (2001) menemukan bahwa inflasi berpengaruh positif terhadap harga saham. Firm size berpengaruh signifikan negatif terhadap P/E. Ukuran perusahaan dapat menurunkan harga saham dibandingkan laba setiap lembar saham. 


\section{SIMPULAN}

Penelitian ini merupakan studi empiris pengaruh Financial Leverage dengan proksi Debt to Equity (DER), foreign ownership, Inflasi dan firm size terhadap price to earning ratio (P/E). Penelitian menggunakan sampel perusahaan non keuangan yang terdapat di Bursa Efek Indonesia (BEI) tahun 2012-2016. Penelitian ini menggunakan metode fixed effect dengan Panel Lease Square pada E-Views 9th Edition.

Hasil penelitian ini adalah secarasimultan menunjukkan bahwa financial leverage dengan proksi Debt to Equity (DER), foreign ownership, Inflasi dan firm sizeberpengaruh positif signifikan (signifikansi 0,000$)$ terhadap price to earning ratio $(\mathrm{P} / \mathrm{E})$.Secaraparsial menunjukkan bahwa Financial leverage berpengaruh negatif signifikan (signifikansi 0,000) terhadap P/E. Foreign ownership berpengaruh negatif signifikan (signifikansi 0,000) terhadap P/E. Inflasi tidakberpengaruhterhadap PE. Firm Size berpengaruh negatif signifikan (signifikansi 0,000) terhadap P/E.

\section{IMPLIKASI}

Penelitian ini bermanfaat bagi pemegang saham, manajemen perusahaan dan pemerintah dalam mengambil kebijakan berkaitan dengan investasi kepemilikan asing, hutang dan sensitifitas investor terhadap laba perusahaan di pasar saham. Penelitian selanjutnya dapat mengembangkan penelitian ini dengan menambahkan variabel lain misalnya kepemilikan manajerial dan variabel ekonomi makro lainnya.

\section{DAFTAR RUJUKAN}

Abbasi, Ebrahim dan Pagghe, Araz M. (2013). The Relationship Between Inflation, Price Earnings Ratio (P/E) And Price Behavior Of Stocks In Tehran Stock Exchange. International Research Journal of Management Sciences. Vol., 1 (4), 98-104.

Agustina, Tenti. (2006). Kepemilikan Asing Perusahaan BEJ, Book to Equity Ratio, Foreign Ownership,Informasi Asimetri,Return on Assets,PriceEarning Ratio. Tesis MM UGM.Http://etd.repository.ugm.ac.id/index.php?mod=penelitian_detail\&sub=PenelitianD etail\&act=view\&typ=html\&buku_id=30942

Azizi A, (1999). Detecting the effective macroeconomic variables on the stock price index. $\mathrm{PhD}$ Thesis, Allameh Tabatabaii University, Iran.

Bai, Chong E., Liu, Q., Lu J., Song, Frank M., And Zhang, J. (2004). Corporate governance and market valuation in China. Journal of Comparative Economics 32, 599-616.

Basu, S. (1977). Investment Performance of Common Stock In Relation Their Price To Earning Ratio : A Test of Efficient Market Hypothesis Test. The Journal Of Finance, Vol.32, No.3, 663-682.

Bayati M, (2005). Correlation between inflation, stock price index, price index and cash returns of stock exchange. MS Thesis, Allameh Tabatabaii University Iran.

Chira, Inga dan Houmes, R. 2015. The effect of ownership structure on the price earnings ratioreturns anomaly. International Review of Financial Analysis, Volume 37, January 2015, Pages 140-147.

Dave E. A. L. Henrietta and C.Martyn. 1998. Predicting Earnings Growth Using Earnings- Price Ratios. Australian Evidence.Australian Journal Of Management. ( June 01, 1998).

Fairfield P.M. 1994. P/E, P/B and the Present Value of Future Dividends. Financial Analysts Journal.Vol. 50 No. 4 (1994), pp 23-31. 
Farooque, Omar Al, Tony van Zijl, Keitha D., AKM Waresul K. (2007). Corporate Governance in Bangladesh: Link between Ownership and Financial Performance, Blackwell Publishing Ltd. Journal Compilation, 15 (6), 1453-1468.

Goel, Utkarsh et al. (2015) . Operating liquidity and financial leverage: Evidences from Indian machinery industry. Procedia - Social and Behavioral Sciences 189 ( 2015 ) $344-350$.

Goyal A, welch I, (2003). Predicting the equity premium with dividend ratios.Management Science Journal. 49(5): 639-654.

Hermuningsih, Sri. (2012). Pengantar Pasar Modal INDONESIA.Yogyakarta: UPP STIM YKPN.

Jensen, M. 1986. Agency costs of free cash flow, corporate finance, and takeovers. American Economic Review, 76(2), 323e329.

Jensen, M. C., and Meckling W. H. 1976. The theory of the firm: Managerial behavior, agency cost and theory ownership structure. Journal of Financial Economics, 3, 305-360

Li, Kai; Yue, Heng; Zhao,Longkai. (2009). Ownership, institutions, and capital structure: Evidence from China. Journal of Comparative Economics 37 (2009) 471-490

Mahmood W.M. W., R. Zakaria. (2007).Profitability and Capital Structure of the Property and construction Sectors in Malaysia. Pacific Rim Property Research Journal Vol. 13 No. 1 (2007).

Malkiel B.G. and J.G.Cragg. (1970). Expectation and The Structure of Share Price. American Economic Review 60.

Marli, Sumarsono Dan Ismail, M. (2010). Analisis Variabel yang Mempengaruhi Price Earning Ratio Dalam Penilaian Harga Saham Di Bursa Efek Jakarta (Tahun 1998 - 2001). Wacana Vol. 13 No.2. April 2010. ISSN. 1411-0199

McWilliams J. D. “ Prices, Earnings and P/E ratios.” Financial Analysts Journal, (May- June, 1966), 1966, ppl37-142.

Mulyani, L dan Pitaloka, E. (2017). Pengaruh Return on Equity, Earning per Share (EPS), dan Debt to Equity Ratio terhadap Price Earning Ratio (PER) Pada PT Indofood Sukses Makmur. Tbk Periode 2012-2014.Widyakala Volume 4 No.1 Maret 2017. ISSN : 23377313 print.

Modigliani, F. \& Miller M.H. 1958. The cost of capital, corporation finance and the theory of investment, American Economic, 48 (3), pp. 261-297.

Modigliani, F. \& Miller M.H. (1963). Corporate income taxes and the cost of capital: a correction, American Economic Review, 53, pp. 433-443

Moeliadji, Arie Sandjaya. (2010). Pengaruh financial leverage terhadap return on equity, earnings per share, price earnings ratio dan risiko sistematis: pada perusahaan yang termasuk dalam anggota LQ 45 di Bursa Efek Indonesia tahun 2003-2007. Bachelor thesis, Petra Christian University.

Myers, S. C. 1977. Determinants of corporate borrowing. Journal of Financial Economics, 5(2), 147-175.

Myers, S.C. and Majluf, N.C. (1984). Corporate financing and investment decisions when firms have information that investors do not have. Journal of Financial Economics, Vol. 13, pp. 187-222.

Ross, S.A. (1977), "The determination of financial structure: the incentive-signaling approach", Bell Journal of Economics, Vol. 8 No. 1, pp. 209-43.

Salvatore, Dominick. (2005). Managerial Economic. Salemba Empat, Jakarta.

Sartono, Agus dan Munir, Misbahul. 1999. Pengaruh Kategori Industri Terhadap Price To Earning Ratio Dan Faktor Penentunya. Jurnal Ekonomi dan Bisnis Indonesia 1997, $X I I(3)$.

Shyu, Jonchi. (2013). Ownership structure, capital structure, and performance of group affiliation. Managerial Finance, Vol. 39 Iss 4 pp. $404-420$ 
Pietrovit, Filomena. (2016). Do price-earnings ratios explain investment decisions better than Tobin's $q$ ? Evidence from German firm-level data. Applied Economics Volume 48, 2016 Issue 34.

Tandelilin, Eduardus. (2008). Analisis Investasi dan Manajemen Portofolio. Yogyakarta:Kanisius

Wiwattanakantang, Yupana. (1999). An empirical study on the determinants of the capital structure of thai firms. Pasific-BasinFinance Journal 7, 371-403.

Yahyaeizadeh Far M, Jafari Samimi A, (2001). Studying the correlation between inflation and stock returns, theoretical analyzing review of literature. Science and Research Journal of Humanities. 11: 115-158. 